\title{
Evaluating multi-locus phylogenies for species boundaries determination in the genus Diaporthe
}

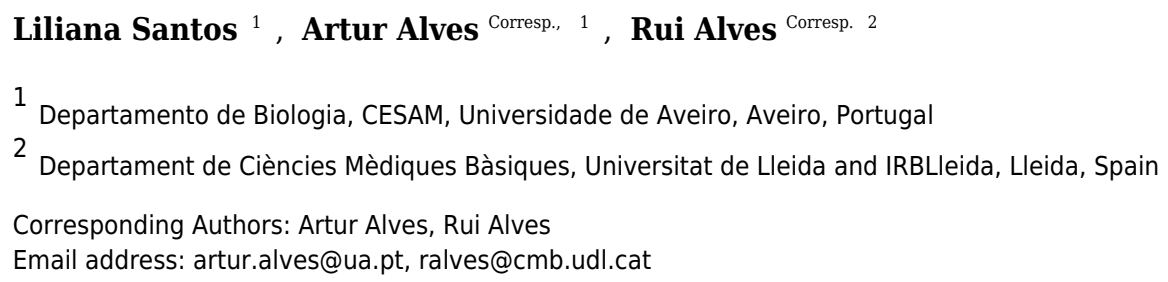

Background. Species identification is essential for controlling disease, understanding epidemiology, and to guide the implementation of phytosanitary measures against fungi from the genus Diaporthe. Accurate Diaporthe species separation requires using multi-loci phylogenies. However, defining the optimal set of loci that can be used for species identification is still an open problem. Methods. Here, we addressed that problem by identifying five loci that have been sequenced in 142 Diaporthe isolates representing 96 species: TEF1, TUB, CAL, HIS and ITS. We then used every possible combination of those loci to build, analyse, and compare phylogenetic trees. Results. As expected, species separation is better when all five loci are simultaneously used to build the phylogeny of the isolates. However, removing the ITS locus has little effect on reconstructed phylogenies, identifying the TEF1-TUB-CAL-HIS four loci tree as almost equivalent to the five loci tree. We further identify the best 3-loci, 2-loci, and 1-locus trees that should be used for species separation in the genus. Discussion. Our results question the current use of the ITS locus for DNA barcoding in the genus Diaporthe and suggest that TEF1 might be a better choice if one locus barcoding needs to be done. 
1 Title: Evaluating multi-locus phylogenies for species boundaries determination in the genus

2 Diaporthe

3

4 Short title: Multi-locus phylogenies for Diaporthe

5

6

7 Liliana Santos ${ }^{1}$, Artur Alves ${ }^{1 *}$ and Rui Alves ${ }^{2 *}$

8

9 Affiliations:

$10{ }^{1}$ Departamento de Biologia, CESAM, Universidade de Aveiro, Campus de Santiago, 3810-193

11 Aveiro, Portugal

12 Dept Ciències Mèdiques Bàsiques, Universitat de Lleida \& IRBLleida, Edific de Recerca

13 Biomèdica I, Av. Rovira Roure 80, 25198 Lleida, Spain

14

$15 *$ Corresponding authors

16 Artur Alves, artur.alves@ua.pt

17 Rui Alves, ralves@cmb.udl.cat 


\section{Abstract}

Background. Species identification is essential for controlling disease, understanding epidemiology, and to guide the implementation of phytosanitary measures against fungi from the genus Diaporthe. Accurate Diaporthe species separation requires using multi-loci phylogenies. However, defining the optimal set of loci that can be used for species identification is still an open problem.

Methods. Here, we addressed that problem by identifying five loci that have been sequenced in 142 Diaporthe isolates representing 96 species: TEF1, TUB, CAL, HIS and ITS. We then used every possible combination of those loci to build, analyse, and compare phylogenetic trees.

Results. As expected, species separation is better when all five loci are simultaneously used to build the phylogeny of the isolates. However, removing the ITS locus has little effect on reconstructed phylogenies, identifying the TEF1-TUB-CAL-HIS four loci tree as almost equivalent to the five loci tree. We further identify the best 3-loci, 2-loci, and 1-locus trees that

41 should be used for species separation in the genus.

Discussion. Our results question the current use of the ITS locus for DNA barcoding in the genus Diaporthe and suggest that TEF1 might be a better choice if one locus barcoding needs to be done. 


\section{Introduction}

51

Species in the ascomycete genus Diaporthe have been identified all over the world. Typically, Diaporthe species are saprobes, endophytes, or plant pathogens (Webber \& Gibbs, 1984; Boddy \& Griffith, 1989; Udayanga et al., 2011). Some plant pathogenic Diaporthe species are associated with cankers, diebacks, rots, spots and wilts on a wide range of plants, some of which are of economic importance as is the case of citrus, cucurbits, soybeans, eggplant, berries and grapevines (Backman, Weaver \& Morgan-Jones, 1985; Merrin, Nair \& Tarran, 1995; Farr, Castlebury \& Rossman, 2002; Farr et al., 2002; Shishido et al., 2006). Less frequently, Diaporthe species can also cause lupinosis and other health problems in humans and other mammals (Van Warmelo \& Marasas, 1972; Sutton et al., 1999; Battilani et al., 2011; GarciaReyne et al., 2011).

Distinction between Diaporthe species has historically been based on an approach that combined morphological information, cultural characteristics, and host affiliation (Udayanga et al., 2011). This approach made it difficult to reliably discriminate between the various members of the genus, because many of these fungi are asexual with low host specificity (Rehner \& Uecker, 1994; Murali, Suryanarayanan \& Geeta, 2006). As a consequence, an unnecessary increase in the number of proposed Diaporthe species occurred. This number currently stands at 977 and 1099 for Diaporthe and 980 and 1047 for Phomopsis in Index Fungorum and Mycobank, respectively (both accessed 14 November 2016). The extinction of the dual nomenclature system for fungi raised the question about which generic name to use, Diaporthe or that of its asexual morph Phomopsis. Given that both names are well known among plant pathologists, and have been equally used, Rossman et al. (2015) proposed that the genus name Diaporthe should be retained over Phomopsis because it was introduced first and therefore has priority.

The problem of incorrect species attribution has practical consequences for the study of this genus, because accurate species identification is essential for understanding the epidemiology, 
75 for controlling plant diseases, and to guide the implementation of international phytosanitary measures (Santos and Phillips, 2009; Udayanga et al., 2011). Therefore, there was an urgent need to reformulate species identification in the genus Diaporthe (Santos and Phillips, 2009).

Advances in the areas of gene sequencing and molecular evolution over the last 50 years have led to the notion that ribosomal genes can be used to distinguish between species and study their molecular evolution (Woese \& Fox, 1977). The choice of these genes comes from the fact that their function is conserved over all living organisms, which has been assumed to imply that their evolutionary rate should be roughly constant over the tree of life.

The molecular evolution studies mentioned have been used to develop general fungal classifications (Shenoy, Jeewon \& Hyde, 2007) and have also been used for species reclassification in the genus Diaporthe (Santos and Phillips 2009; Santos et al., 2011; Thompson et al., 2011; Baumgartner et al., 2013; Gomes et al, 2013; Huang et al., 2013; Tan et al., 2013; Gao et al., 2014; Udayanga et al., 2014a; Udayanga et al., 2014b). In fact, recently the ITS region of the ribosomal genes has been accepted as the official fungal barcode (Schoch et al., 2012), and its sequence is frequently used for molecular phylogeny analysis of Diaporthe species.

However, assuming that ribosomal gene sequences evolve at a uniform rate, independent of species is sometimes incorrect (Anderson \& Stasovski, 1992; O'Donnell, 1992; Carbone \& Kohn, 1993). In addition, due to the strong constraints imposed by ribosome function on the mutations in the sequence of ribosomal genes, close microbial species may have identical rDNA sequences, while having clearly different genomes. For example, a comparison between Cladosporium, Penicillium and Fusarium species at the NCBI Genome and GenBank databases (Schoch et al., 2012) will confirm this statement. Such considerations suggested that phylogenetic trees based on sets of genes are potentially more powerful in solving species boundaries than phylogenetic trees based on any single genes, as the former trees contain information about the simultaneous evolution of various biological processes (Olmstead \& Sweere, 1994; Rokas et al., 2003).

The possibility of using full genomes to create phylogenetic trees becomes more feasible as the number of fully sequenced genomes increases. For example, the full genomic complement of 
104

105

106

107

108

109

110

111

112

113

114

115

116

117

118

119

120

121

122

123

124

125

126

127

128

129

130

131

132

genes/proteins involved in metabolism have been used to reconstruct phylogenies that provide information regarding the evolution of metabolism in various species (Heymans \& Singh, 2003; Ma \& Zeng, 2004; Forst et al., 2006; Oh et al., 2006). This type of genome wide phylogeny reconstruction is impossible for organisms that have not had their genomes fully sequenced and annotated. This is the case for the genus Diaporthe, for which the first genome sequencing project started in 2013 (GOLD project Gp0038530) and until now only Diaporthe species have their genome sequenced (Phomopsis longicolla, Diaporthe aspalathi, Diaporthe ampelina and Diaporthe helianthi) (Li et al., 2015; Baroncelli et al., 2016; Li et al., 2016; Savitha et al., 2016).

Although full genome sequences are still forthcoming for Diaporthe species, current species identification and phylogeny reconstruction in the genus are already largely dependent on molecular sequences (Santos, Correia \& Phillips, 2010). The sequences more frequently used for these studies are: large subunit (LSU) of the ribosomal DNA, intergenic spacers (IGS) of the ribosomal DNA, internal transcribed spacer (ITS) of the ribosomal DNA, translation elongation factor 1- $\alpha(T E F 1)$ gene, $\beta$-tubulin (TUB) gene, histone (HIS) gene, calmodulin $(C A L)$ gene, actin $(A C T)$ gene, DNA-lyase (APN2) gene, 60s ribosomal protein L37 (FG1093) gene and mating type genes (MAT-1-1-1 and MAT-1-2-1) (Farr, Castlebury \& Rossman, 2002; Farr et al., 2002; Castlebury et al., 2003; Pecchia, Mercatelli \& Vannacci, 2004; Schilder et al., 2005; Van Rensburg et al., 2006; Kanematsu, Adachi \& Ito, 2007; Santos, Correia \& Phillips, 2010; Santos et al., 2011; Thompson et al., 2011; Grasso et al., 2012; Sun et al., 2012; Udayanga et al., 2012; Baumgartner et al., 2013; Bienapfl \& Balci, 2013; Gomes et al., 2013; Huang et al., 2013; Sun et al., 2013; Tan et al., 2013;Vidić et al., 2013; Gao et al., 2014; Udayanga et al., 2014a; Udayanga et al., 2014b; Wang et al., 2014).

However, multi-locus phylogenies for the genus Diaporthe have only been developed in the last few years (Schielder et al., 2005; Van Rensburg et al., 2006; Udayanga et al., 2012; Baumgartner et al., 2013; Gomes et al., 2013; Huang et al., 2013; Tan et al., 2013; Gao et al., 2014; Udayanga et al., 2014a; Udayanga et al., 2014b; Wang et al., 2014). In fact, creating phylogenies that include several loci is still possible only for a limited set of species from the genus Diaporthe, because not all genes have been sequenced for all tentative species. This is due to many reasons, among which the lack of resources that prevents unlimited sequencing of samples. Nevertheless, 
133 a multi-locus approach should always be used for accurate resolution of species in the genus 134 Diaporthe.

135 In recent studies the maximum number of loci used was to create multi loci phylogenies seven 136 (TEF1, TUB, HIS, CAL, ACT, APN2 and FG1093), simultaneously sequenced across 137 approximately 80 isolates from 9 Diaporthe species (Udayanga et al., 2014a). These loci were 138 used to establish the specific limits of $D$. eres. This work provides a good example of how to 139 establish the boundaries for one species within the genus Diaporthe. However, if this is to be 140 extended to the other species of the genus, it is important to determine which loci are the most 141 informative to be sequenced and used in a much wider range of Diaporthe species.

142 With this in mind we asked which combination of frequently sequenced loci better discriminate 143 species boundaries in Diaporthe. To answer this question, we considered the ITS, TEF1, TUB, 144 HIS and CAL loci, which had been sequenced for 96 different Diaporthe species. This paper ranks these loci according to their contribution for improving/decreasing the resolution of Diaporthe species determination, as they are added/removed from multi-locus phylogenies 147 analysis.

\section{Materials \& Methods}

\subsection{Data collection}

151

152

153

154

155

156

157

158

159

In-house PERL scripts were used to search the GenBank and download all sequences from Diaporthe and Phomopsis species for the 11 loci mentioned in the introduction. We then determined that sequences for ITS, CAL, TUB, HIS, and TEF1 loci were known in 142 Diaporthe and Phomopsis isolates, corresponding to 96 different species. Adding any other loci would reduce the number of species. Thus, we have chosen to study these five loci in those 96 species, as a way of maximizing the statistical power of our analysis. Species and gene identifications, as well as, the accession numbers are given in SM Table 1. The current study used 142 Diaporthe isolates that were selected by choosing two isolates per species (whenever they were available), at least one of them being an ex-type isolate. With these constrains in mind, 
160 we chose the two isolates for which the sequences were more dissimilar within the same species,

161 in order to maximize intraspecific sequence diversity.

162 Also considering this intraspecific heterogeneity, we used a larger number of sequence sample 163 for Diaporthe species complexes (Udayanga et al., 2014a). These are species with a higher than 164 average diversity between individuals. In our case they include $D$. sojae, $D$. foeniculacea, and $D$. 165 eres. For example, the D. eres complex includes strains CBS 113470, CBS 116953, CBS 200.39, 166 and CBS 338.89, some of which were originally classified as D. nobilis and later reclassified into 167 the D. eres complex (Gomes et al. 2013; Udayanga et al. 2014a). In addition, we used more than 168 one ex-type isolate for the species complexes, because these species are highly heterogeneous. 169 All sequence data used in this study have been validated and published previously (Castleburry 170 et al., 2002; Van Niekerk et al., 2005; Santos et al., 2011, Gomes et al., 2013 and Udayanga et 171 al., 2014a).

172 As species concept we used the criteria of Genealogical Concordance Phylogenetic Species 173 Recognition (GCPSR) to resolve species boundaries based on individual and combined analyses 174 of the 5 genes.

\subsection{Sequence alignment and phylogenetic analyses}

176 Five multiple alignments, one per locus, were created using the software ClustalX2.1 (Larkin et al., 2007), and the following parameters: pairwise alignment parameters (gap opening =10, gap extension $=0.1$ ) and multiple alignment parameters $($ gap opening $=10$, gap extension $=0.2$, transition weight $=0.5$, delay divergent sequences $=25 \%$ ), and optimized manually with BioEdit (Hall, 1999). The alignments for the individual locus were then concatenated into all possible combinations of 2, 3, 4, and five loci. This generated 31 alternatives multiple alignments, counting the 5 multiple alignments for the individual genes and the alignment for the five concatenated gene sequences. MEGA6 (Tamura et al., 2013) was used to create and analyse phylogenetic trees for each of the 31 alignments, independently using two alternative methods (Maximum Parsimony [MP] and Maximum Likelihood [ML]; Li, 1997). MEGA6 was also used to determine the best evolution models to be used for building the ML tree from each multiple alignment, as described previously (Tamura et al., 2013). These models are listed in Table 1.

188 Each tree was bootstrapped 1000 times, and branches that split in less than $90 \%$ of the 1000 trees 
189 were condensed. MP trees were obtained using the Tree-Bisection-Reconnection (TBR) 190 algorithm (Nei \& Kumar, 2000) with search level 1, in which the initial trees were obtained by 191 the random addition of sequences (10 replicates). The initial trees for the heuristic ML search 192 were obtained by applying the Neighbor-Joining method to a matrix of pairwise distances estimated using the Maximum Composite Likelihood (MCL) approach, allowing for some sites to be evolutionarily invariable $([+\mathrm{I}], 0.0000 \%$ sites). As in Gomes et al. (2013), we choose Diaporthella corylina (CBS 121124) as outgroup.

\subsection{Comparing trees}

\subsubsection{Tree scores}

MEGA6 was used to create and analyse all MP and ML phylogenetic trees. As a first approximation, we compare the likelihood values between ML trees and the MP scores between MP trees (Table 2 and 3) for identifying the best and worst trees of each type.

The length of an MP tree estimates phylogenetic tree resolution. This value is also dependent on the length of the sequences that are used to build the tree. This means that comparing tree lengths for trees built using a varying number of loci should also consider normalizing the length of the tree by the corresponding size of the aligned sequence (Table 2). This normalization allows us to estimate which loci provide more added value when it comes to species resolution.

ML tree building methods seek the tree that is more likely (the highest likelihood), based on a probabilistic model of sequence evolution. The best ML tree has the lowest - log likelihood scores and worst ML tree has the highest - log likelihood value. This likelihood is also dependent on the length of the alignment. In order to be able to compare all the trees among them we also normalized the values of - log Likelihood in the same way of the MP length (Table 3). This means that comparing tree log likelihoods for trees built using a varying number of loci should also consider normalizing the log likelihood of the tree by the corresponding size of the aligned sequence (Table 3 ).

\subsubsection{Tree distances}

All trees we build have the same species. Thus, we are able to measure the difference between every possible pair of trees, based on the analysis of the symmetric distance between equal leafs 
217 in two trees (Robinson \& Foulds, 1981). This distance was calculated for all pairs of MP trees 218 using the Treedist methods of the PHYLIP suite of programs (Felsenstein, 1989). The same 219 calculations were made for all pairs of ML trees. For these calculations we used condensed trees 220 with a 90\% bootstrap cut-off value. This allows us to measure how adding/removing a locus 221 to/from the multiple alignments causes the resulting phylogenetic tree to change. 2.3.3. Testing Phylogenetic informativeness and identification of species boundaries.

223

224

225

226

227

228

229

230

231

232

233

234

235

236

237

238

239

240

241

242

243

\section{Results}

We analyse 142 isolates from 96 Diaporthe species for which the ITS, CAL, TUB, HIS, and TEF1 loci had been sequenced (SM Table 1). The alignments for each locus were then concatenated in all possible 31 combinations of 1, 2, 3, 4, and 5 genes. Alignment characteristics for this study are reported in Table 4. Each combination was used to build a ML and ME phylogenetic trees. Each tree was bootstrapped 1000 times and every tree used is a condensed tree with a 90\% cut-off. Alignments and trees were deposited in TreeBase (Study Accession: S20343).

\subsection{Best and worst resolving phylogenetic trees}

The "quality" (resolution) of the individual phylogenetic trees was determined as described in methods.

Figures 1 and 2 present the condensed MP and ML trees build from the concatenated multiple alignments of the 5 loci, respectively. Phylograms showing all complete trees are given as supplementary figures (SM Figure 1 and 2, respectively). These trees are the best resolving trees built for each method, as indicated by the scores shown in Table 2 for MP trees and in Table 3 for ML trees. 
244 The increase in tree length (Table 2) and log-likelihood scores (Table 3) of the trees with the

245 increase in number of loci indicates that resolution of the trees is directly correlated with the 246 number of loci used to build them. This is also true for the tree scores and log-likelihood scores 247 normalized by alignment length. Thus, the worst trees are built using the multiple alignments for 248 only one locus. Within the one-locus trees, the best MP (Figure 3 and SM - Figure 3) and ML 249 (Figure 4 and SM - Figure 4) condensed trees are shown in Figure 3 and 4. TEF1 trees have the 250 highest values for length and-log likelihood.

\subsection{Choosing the most informative loci for sequencing}

252

253

254

255

256

257

258

259

260

261

262

263

264

265

266

267

268

269

270

271

272

The previous results indicate that, whenever possible, all five loci should be sequenced, in order to better differentiate between Diaporthe species. However, this might not always be possible. In situations where only a subset of one, two, three, or four out of the five loci can be sequenced, which sequences might be more informative? This can be roughly answered in two steps.

The first step is done by measuring how adding/removing a locus to/from the multiple alignments causes the resulting phylogenetic tree to change. These changes can be measured by calculating the symmetric distance between the two trees and by analysing if species resolution changes when the relevant locus is added or removed. The smaller the changes are, the less informative the locus is. The symmetric distance matrices between every pair of MP (SM Table 2) or ML (SM Table 3) trees were calculated as described in methods. Table 5 summarize these results and show how many changes are observed on average when a specific locus is removed from a multi-locus tree. On average, the ITS locus is the least informative one, closely followed by the HIS locus. The third locus whose removal causes the least changes in the trees is CAL. This is true for both, the MP and the ML trees.

The second step is done by evaluating the changes in the resolution of the trees when a locus is removed from the multiple alignments. A more detailed analysis of Tables 3-5 reveals that removing the ITS locus from any MP or ML multi-loci tree causes the smallest decrease in MP tree length and in ML tree likelihood. Hence, if only four loci can be sequenced these should be TEF1-TUB-CAL-HIS. The second locus with the least effect in tree resolution is $T U B$, closely followed by HIS. Given that, as measured in step one of the process, average differences between trees when $H I S$ is removed are much smaller than differences between trees when $T U B$ is 
273 removed, if only three loci can be sequenced these should be TEF1-TUB-CAL. If only two loci

274 can be sequenced, we suggest TEF 1-TUB, as removing CAL has the least average effect on trees.

275 Finally, if only one locus can be sequenced tree resolution suggests that this locus should be

276 TEF1. TEF1 trees are the best single locus MP and ML trees (Figure 3 and 4).

\subsection{Phylogenetic informativeness and identification of species boundaries}

278

279

280

281

282

283

284

285

286

287

288

289

290

291

292

293

294

295

296

297

298

299

300

Figure 5 shows that the TEF1 sequence is the most informative for species separation, both globally and per alignment site. In addition, we also see that the ITS sequence is the least informative to resolve Diaporthe species (Figure 5). The five loci can be ranked from most to least informative for Diaporthe species separation as follows: TEF $1>H I S>C A L>T U B>I T S$.

The dataset we used for this analysis is as close as we currently can get to a standard set of well separated Diaporthe species, taking into account that the five loci we analyse needed to be sequenced for all individuals in the set. Taking this into account, an inspection of the trees is required to understand, on top of all the statistical analyses, if species are well separated or not.

We see that, in general, the addition of a new locus to the alignment decreases the number of isolates from the same species that do not cluster together (separation errors). Therefore, the tree of 5 loci has less separation errors than 4-loci trees, which in turn have less separation errors than the 3-loci trees, and so on. As expected from our previous analysis, the TEF1 tree provides the best single locus ML tree, TEF1-TUB tree provides the best 2-loci ML tree, TEF1-TUB-CAL the best 3-locus ML tree. The results from the MP trees are qualitatively similar although, in general, these trees have more separation errors that the ML ones.

\section{Discussion}

Identifying species boundaries in organisms is a difficult task, as theoretical and practical definitions of species are not always consistent with each other (Doolittle \& Zhaxybayeva, 2009; Giraud et al., 2008). While Woese \& Fox (1977) suggested using ribosomal sequences to define species borders, such sequences are not always the best choice. For example, searching GenBank will reveal that some Cladosporium, Penicillium and Fusarium species cannot be differentiated using ITS (Schoch et al., 2012). 
301 More recent work suggests that trees based on multi-loci sequence analysis (MLSA) provide 302 more accurate estimations of phylogeny than single gene trees, if appropriate loci are used 303 (Gadagkar, Rosenberg \& Kumar, 2005; Mirarab, Bayzid \& Warnow, 2014). Briefly, MLSA 304 concatenates sequence alignments from multiple genes and uses the concatenated sequences to 305 determine phylogenetic relationships. This method appears to more optimally resolve the 306 phylogenetic position of species in the same or in closely related genera (Hanage, Fraser \& 307 Spratt, 2006). An increase in the number of loci used to build MLSA phylogenetic trees 308 positively correlates to sensitivity and accuracy in species separation (Rokas et al., 2003; 309 Udayanga et al., 2011). In contrast, increasing the number of species in the alignment leads to a 310 decrease in the ability to separate them accurately, unless a higher number of appropriate loci are 311 used to maintain the quality of that separation (Bininda-Emonds et al. 2001; Kim, 1998; Poe \& 312 Swofford, 1999; Rokas et al., 2003; Udayanga et al., 2011). The choice of appropriate loci to be 313 used in such trees can be optimized in genera with a large number of sequenced genomes, 314 because in such cases it is possible to make full genome studies to identify the best set of loci to 315 separate species. Nevertheless, the amount of information that must be analysed for doing so 316 could become prohibitive (Thangaduras \& Sangeetha, 2013).

317 The choice of appropriate loci that optimizes species separation is harder when fully sequenced 318 genomes are not available, as is the case for the genus Diaporthe. Nevertheless, MLSA 319 phylogenetic studies of Diaporthe species have been done using loci that have been chosen in a more or less ad hoc manner, by taking into account how conserved they were in different fungal genus (Baumgartner et al., 2013; Gao et al., 2014; Gomes et al., 2013; Huang et al., 2013;

322 Schielder et al., 2005; Tan et al., 2013; Udayanga et al., 2012; Udayanga et al., 2014a; Udayanga 323 et al., 2014b; Van Rensburg et al., 2006; Wang et al., 2014). In general, these studies show that 324 MLSA phylogenetic trees provide higher resolution for Diaporthe species than single locus 325 phylogenetic trees (Huang et al., 2013; Udayanga et al. 2012; Van Rensberg et al., 2006).

326 The current study addresses the problem of which loci are best for accurate species separation in 327 the genus Diaporthe in a systematic manner. Walker et al. (2012) performed a similar study. 328 While we use five non-coding loci to study species separation in Diaporthe, those authors 329 employed two single copy protein-coding genes (FG1093 and MS204) to study species 330 separation in Sordariomycetes. While Walker et al. (2012) analysed various aspects of codon 
331 conservation and substitution rates, these analyses are meaningless for our sequence dataset. The

332 use of non-coding sequences is favoured in Diaporthe species separation because coding 333 sequences are typically too conserved to allow for appropriate separation within the genus.

334 The major contributions of this paper are two-fold. First, our work confirms that the quality of 335 species separation in phylogenetic trees increases with the number of loci used to build phylogenetic trees. Second and more importantly it identifies the best combination of loci that one should use for building those phylogenetic trees, if only one, two, three, or four loci can be sequenced. To achieve this, we took the most commonly sequenced loci for 142 Diaporthe isolates and studied which loci optimize species differentiation in the genus. We chose only loci that are commonly sequenced for members of the genus. Then, we selected a sequence dataset that was experimentally validated by others (Castleburry et al., 2002; Van Niekerk et al., 2005; Santos et al., 2011 and Gomes et al., 2013) before being deposited in GenBank. Whenever possible we favoured sequences from ex-type isolates and produced via low throughput, high fidelity, sequencing methods. In addition, our sequence selection maximized intraspecific sequence variation, which in turn maximizes the possibility that intra-specific hyperdiversity could be higher than interspecific diversity. Thus, species separation through phylogenetic trees in our sample is made more difficult by our sequence selection, making our analysis more robust. In this paper we only show and analyse condensed MP and ML trees, using a cut-off of 90\%, which means that our trees are very robust to gene order, as a significant amount of bootstrapping was used to calculate them. In fact, to test that, we performed a side experiment where we changed the order of the locus sequences in the alignments and recalculated the trees (SM - Figure 5).

353
We found that species differentiation is optimized by creating phylogenetic trees built from the multiple sequence alignment of five loci: TEF1-TUB-HIS-CAL-ITS. However, little information is lost when ITS locus is removed and only the other four loci are used to simultaneously build the phylogeny. In addition, we also provide researchers with a ranking of best loci to sequence if only $1,2,3$, or 4 of the loci can be sequenced.

It may be surprising that the ribosomal ITS locus is the least informative of the five loci when it comes to separating Diaporthe species. However, Santos, Correia \& Phillips (2010) found that 
360 the ITS region in Diaporthe is evolving at much faster rates than TEF1 or even MAT genes.

361 Hence, what seems to be happening is that ITS sequences present a wider variation than is 362 advisable for creating precise species boundaries. Therefore a slowly evolving gene region 363 should be utilized in order to establish precise species limits (Udayanga et al., 2012).

364 DNA barcoding (Kress et al., 2014) refers to the use of standard short gene sequences to identify 365 species. The use of DNA barcoding implies that an effort should be made to standardize the use 366 of the loci for phylogenetic studies. ITS is the official DNA barcode region in fungi (Schoch et 367 al., 2012). This work supports previous studies whose results suggest that using ITS as a standard 368 for species separation in fungi should be discontinued (Gomes et al., 2013; Thangaduras \& 369 Sangeetha 2013). Our results strongly recommend that TEF1 should be used instead, at least in 370 the genus Diaporthe. This is consistent with and further develops previously published results, 371 which proposed either TEF1, HIS, or APN2 as alternative locus for barcoding in the genus 372 (Santos, Correia \& Phillips, 2010; Udayanga et al., 2014b). However, Gomes et al. (2013), using 373 Bayesian analysis, consider HIS and TUB as best resolving genes. Nevertheless, considering that 374 Gomes et al. (2013) use shorter sequences than those used here, one is tempted to cautiously 375 analyse and reinterpret their conclusions.

376 Despite the TEF tree appears to be a better species separator than the 5 loci tree, the true is that, 377 the alignment used to build the 5 loci tree is roughly five times larger than that for the TEF tree. 378 This means that, with a larger number of positions, there is bound to be more variability in the 379 bootstrapping of the 5 loci tree than in the bootstrapping of the TEF tree. Hence, the observation 380 that the $T E F$ give better resolution than 5 loci results from a statistical artefact. This fact occurs 381 when focusing on the D. eres complex clade. For example, in the case of the D. eres complex, all 382 the species are grouped in the same clade in both cases (D. alleghaniensis, D. alnea, D. 383 celastrina, D. bicincta, D. eres, D. neilliae and D. vaccinii). However, in the 5-loci trees the 384 resolution of this species complex is better. This is especially important as phylogenetic analyses 385 of the $D$. eres complex often revealed ambiguous clades with short branch and moderate statistic 386 supports due to their high variability. Udayanaga et al. (2014a) studied this problematic by using 387 different genes, whose sequences are not available for the other Diaporthe species we consider. 388 Therefore, we could not incorporate their data in our study. We also note that one possible 389 explanation for the observation that some species of the D. eres complex do not "group" in the 
390

391

392

393

394

395

396

397

398

399

400

401

402

403

404

405

406

407

408

409

410

411

412

413

414

415

416

same clade could be due to the fact that they are not really D. eres. However, to test that, we would need to actually obtain samples of the complex, re-sequence and analyse them in order to clarify the species boundaries in this group.

The problem of species boundary identification is very relevant in the genus Diaporthe, where a general taxonomic revision based on molecular analysis is probably overdue. Such a revision could then be used to improve the annotation of sequences in public databases, such as GenBank. For example, many of the sequences we use in our analysis are still assigned to species that have already been reclassified. This also emphasizes that a standard procedure with minimal information required for submitting new Diaporthe species needs to be put in place in order to avoid unnecessary creation of new species (Udayanga et al., 2014b). Furthermore, as also suggested by Gomes et al. (2013) we feel that this revision should be made using molecular data. Any new Diaporthe species report should be accompanied by molecular data that supports the identification of the individual as a new species. In addition, we feel that a proper taxonomic revision of the genus should also consider morphological descriptions and epitypification of species as previously suggested (Gomes et al., 2013; Udayanga et al., 2014b).

(1)

\section{Conclusions}

Our results indicate that:

- In order of effectiveness the best sets of loci for resolving Diaporthe species are TEF1TUB-CAL-HIS-ITS, TEF1-TUB-CAL-HIS, TEF1-TUB-CAL, TEF1-TUB and TEF1.

- The TEF1 locus is a better candidate for single locus DNA barcoding in the genus Diaporthe than the ITS locus.

- Multi-loci DNA barcoding will provide a more accurate species separation in the genus than single locus barcoding. Furthermore, a four loci barcoding including TEF1-TUB$H I S-C A L$ will be almost as effective as a five loci barcoding including ITS-TEF1-TUBHIS-CAL. 


\section{Acknowledgements}

418 We thank Anabel Usié and R. Benfeitas for assistance with the creation of the Perl scripts.

419

420

421

422

423

424

425

426

427

428

429

430

431

432

433

434

435

436

437

438

439

440

441

442

443

444

445

446

447

\section{References}

Anderson JB, Stasovski E. 1992. Molecular phylogeny of northern hemisphere species of Armillaria. Mycologia 84:505-516.

Backman PA, Weaver DB, Morgan-Jones G. 1985. Soybean stem canker: an emerging disease problem. Plant Disease 69:641-647.

Baroncelli R, Scala F, Vergara M, Thon MR, Ruocco M. 2016. Draft whole-genome sequence of the Diaporthe helianthi 7/96 strain, causal agent of sunflower stem canker. Genomics Data 10: 151-152. DOI: http://dx.doi.org/10.1016/j.gdata.2016.11.005

Battilani P, Gualla A, Dall'Asta C, Pellacani C, Galaverna G, Giorni P, Caglieri A, Tagliaferri S, Pietri A, Dossena A, Spadaro D, Marchelli R, Gullino ML, Costa LG. 2011. Phomopsins: an overview of phytopathological and chemical aspects, toxicity, analysis and occurrence. World Mycotoxin Journal 4(4):345-359. DOI:10.3920/WMJ2011.1302.

Baumgartner K, Fujiyoshi PT, Travadon, R, Castlebury LA, Wilcox WF, Rolshausen PE. 2013. Characterization of Species of Diaporthe from Wood Cankers of Grape in Eastern North American Vineyards. Plant Disease 97(7):912-920.

Bienapfl JC, Balci Y. 2013. Phomopsis Blight: A New Disease of Pieris japonica Caused by Phomopsis amygdali in the United States. Plant Disease 97(11):1403-1407.

Bininda-Emonds OR, Brady SG, Kim J, Sanderson MJ. 2001. Scaling of accuracy in extremely large phylogenetic trees. Pacific Symposium on Biocomputing 6:547-558.

Boddy L, Griffith S. 1989. Role of endophytes and latent invasion in the development of decay communities in sapwood of angiospermous trees. SYDOWIA 41:41-73.

Carbone I, Kohn LM. 1993. Ribosomal DNA sequence divergence within internal transcribed spacer 1 of the Sclerotiniaceae. Mycologia 85(3):415-427. DOI:10.2307/3760703.

Castlebury LA, Farr DF, Rossman AY, Jaklitsch W. 2003. Diaporthe angelicae comb. nov., a modern description and placement of Diaporthopsis in Diaporthe. Mycoscience 44(3):203-208. DOI:10.1007/s10267-003-0107-2.

Doolittle WF, Zhaxybayeva O. 2009. On the origin of prokaryotic species. Genome Research, 19(5): 744-756. DOI: 10.1101/gr.086645.108. 
448 Farr DF, Castlebury LA, Rossman AY. 2002. Morphological and molecular characterization of 449 Phomopsis vaccinii and additional isolates of Phomopsis from blueberry and cranberry in the 450 eastern United States. Mycologia 94(3):494-504.

451 Farr DF, Castlebury LA, Rossman AY, Putnam ML. 2002. A new species of Phomopsis causing 452 twig dieback of Vaccinium vitis-idaea (lingonberry). Mycological Research 106(6):745-752.

453 Felsenstein J. 1989. PHYLIP - Phylogeny Inference Package (Version 3.2). Cladistics 5:164454166.

455 Forst CV, Flamm C, Hofacker IL, Stadler PF. 2006. Algebraic comparison of metabolic 456 networks, phylogenetic inference, and metabolic innovation. BMC Bioinformatics 7:67. 457 DOI:10.1186/1471-2105-7-67.

458 Gadagkar SR, Rosenberg MS, Kumar S. 2005. Inferring species phylogenies from multiple 459 genes: concatenated sequence tree versus consensus gene tree. Journal of Experimental Zoology 460 Part B: Molecular and Developmental Evolution 304B (1):64-74. DOI: 10.1002/jez.b.21026.

461 Garcia-Reyne A, López-Medrano F, Morales JM, García EC, Martín I, Eraña I, Meije Y, Lalueza 462 A, Alastruey-Izquierdo A, Rodríguez-Tudela JL, Aquado JM. 2011. Cutaneous infection by 463 Phomopsis longicolla in a renal transplant recipient from Guinea: first report of human infection 464 by this fungus. Transplant Infectious Disease 13:204-207. DOI:10.1111/j.1399-3062.2010.0057.

465 Gao Y, Sun W, Su Y, Cai L. 2014. Three new species of Phomopsis in Gutianshan Nature 466 Reserve in China. Mycological Progress 13:111-121. DOI:10.1007/s11557-013-0898-2.

467 Giraud T, Refrégier G, Le Gac M, de Vienne DM, Hood ME. 2008. Speciation in fungi. Fungal 468 Genetics and Biology 45:791-802. DOI: 10.1016/j.fgb.2008.02.001.

469 Gomes RR, Glienke C, Videira S I.R, Lombard L, Groenewald JZ, Crous PW. 2013. Diaporthe: 470 a genus of endophytic, saprobic and plant pathogenic fungi. Persoonia 31:1-41. 471 DOI:10.3767/003158513X666844.

472 Grasso FM, Marini M, Vitale A, Firrao G, Granata G. 2012. Canker and dieback on Platanus $x$ 473 acerifolia caused by Diaporthe scabra. Forest Pathology 42:510-513. DOI:10.1111/j.1439$474 \quad 0329.2012 .00785 . x$.

475 Hall TA. 1999. BioEdit: a user-friendly biological sequence alignment editor and analysis 476 program for Windows 95/98/NT. Nucleic Acids Symposium 41:95-98.

477 Hanage WP, Fraser C, Spratt BG. 2006. Sequences, sequence clusters and bacterial species. 478 Philosophical Transactions of The Royal Society B - Biological Sciences 361:1917-1927. 
479 Hasegawa M, Kishino H, Yano TA. 1985. Dating of the human ape splitting by a molecular 480 clock of mitochondrial DNA. Journal of Molecular Evolution 22:160-174.

481 Heymans M, Singh AK. 2003. Deriving phylogenetic trees from the similarity analysis of 482 metabolic pathways. Bioinformatics, 19 (suppll): i138-i146. DOI: 483 10.1093/bioinformatics/btg 1018

484 Huang F, Hou X, Dewdney MM, Fu Y, Chen G, Hyde KD, Li H. 2013. Diaporthe species 485 occurring on citrus in China. Fungal Diversity 61:237-250. DOI:10.1007/s13225-013-0245-6.

486 Kanematsu, S., Adachi, Y. and Ito, T. 2007. Mating-type loci of heterothallic Diaporthe spp.: 487 homologous genes are present in opposite mating-types. Current Genetics, 52: 11-22. 488 Doi:10.1007/s00294-007-0132-3.

489 Kim J. 1998. Large-scale phylogenies and measuring the performance of phylogenetic 490 estimators. Systematic Biology 47:43-60.

491 Kress WJ, García-Robledo C, Uriarte M, Erickson DL. 2014. DNA barcodes for ecology, 492 evolution, and conservation. Trends in Ecology \& Evoltion 30(1):25-35. DOI: 493 10.1016/j.tree.2014.10.008.

494 Larkin MA, Blackshields G, Brown NP, Chenna R, McGettigan PA, McWilliam H, Valentin F, 495 Wallace IM, Wilm A, Lopez R, Thompson JD, Gibson TJ, Higgins DG. 2007 Clustal W and 496 Clustal X version 2.0. Bioinformatics 23:2947-2948. DOI: 10.1093/bioinformatics/btm404

497 Li S, Darwish O, Alkharouf N, Matthews B, Ji P, Domier LL, Zhang N, Bluhm BH. 2015. Draft 498 genome sequence of Phomopsis longicolla isolate MSPL 10-6. Genomics Data 3: 55-56. DOI: 499 http://dx.doi.org/10.1016/j.gdata.2014.11.007

500 Li S, Song Q, Martins AM, Cregan P. 2016. Draft genome sequence of Diaporthe aspalathi 501 isolate MS-SSC91, a fungus causing stem canker in soybean. Genomics Data 7: 262-263. DOI: 502 http://dx.doi.org/10.1016/j.gdata.2016.02.002

503 Li W. 1997. Molecular Evolution. Sunderland, Massachusetts, USA: Sinauer and Associates.

504 López-Giráldez F, Townsend JP. 2011. PhyDesign: an online application for profiling 505 phylogenetic informativeness. BMC Evolutionary Biology 11:152. DOI: 10.1186/1471-2148-11$506 \quad 152$

507 Ma H, Zeng A. 2004. Phylogenetic comparison of metabolic capacities of organisms at genome 508 level. Molecular Phylogenetics and Evolution 31(1):204-213.

509 Merrin SJ, Nair NG, Tarran J. 1995. Variation in Phomopsis recorded on grapevine in Australia 510 and its taxonomic and biological implications. Australasian Plant Pathology 24(1):44-56. 
511 Mirarab S, Bayzid MS, Warnow T. 2014. Evaluating Summary Methods for Multilocus Species 512 Tree Estimation in the Presence of Incomplete Lineage Sorting. Systematic Biology syu063. 513 DOI: 10.1093/sysbio/syu063.

514 Murali TS, Suryanarayanan TS, Geeta R. 2006. Endophytic Phomopsis species: host range and 515 implications for diversity estimates. Canadian Journal of Microbiology 52(7):673-680. 516 DOI:10.1139/w06-020.

517 Nei M, Kumar S. 2000. Molecular Evolution and Phylogenetics. New York, USA: Oxford 518 University Press.

519 O'Donnell K. 1992. Ribosomal DNA internal transcribed spacers are highly divergent in the 520 phytopathogenic ascomycete Fusarium sambucinum (Gibberella pulicaris). Current Genetics 521 22(3):213-220. DOI: 10.1007/BF00351728.

522 Oh SJ, Joung J, Chang J, Zang B. 2006. Construction of phylogenetic trees by kernel-based 523 comparative analysis of metabolic networks. BMC Bioinformatics 7:284. DOI:10.1186/1471$524 \quad 2105-7-284$

525 Olmstead RG, Sweere JA. 1994. Combining data in phylogenetic systematics: an empirical 526 approach using three molecular data sets in the Solanaceae. Systematic Biology 43(4):467-481. 527 DOI: 10.1093/sysbio/43.4.467.

528 Pecchia S, Mercatelli E, Vannacci G. 2004. Intraspecific diversity within Diaporthe helianthi: 529 evidence from rDNA intergenic spacer (IGS) sequence analysis. Mycopathologia 157:317-326.

530 Poe S, Swofford DL. 1999. Taxon sampling revisited. Nature 398:299-300. DOI:10.1038/18592

531 Rehner SA, Uecker FA. 1994. Nuclear ribosomal internal transcribed spacer phylogeny and host 532 diversity in the coelomycetes Phomopsis. Canadian Journal of Botany 72(11):1666-1674. DOI: $53310.1139 / \mathrm{b} 94-204$.

534 Robinson DF, Foulds LR. 1981. Comparison of phylogenetic trees. Mathematical Biosciences 535 53:131-147.

536 Rokas A, Williams BL, King N, Carroll, SB. 2003. Genome-scale approaches to resolving 537 incongruence in molecular phylogenies. Nature 425:798-804. DOI: 10.1038/nature02053.

538 Rossman AY, Adams GC, Cannon PF, Castlebury LA, Crous PW, Gryzenhout M, Jaklitsch 539 WM, Mejia LC, Stoykov D, Udayanga D, Voglmayr H, Walker DM. 2015. Recommendations of 540 generic names in Diaporthales competing for protection or use. IMA Fungus 6(1): 145-154. 541 DOI: 10.5598/imafungus.2015.06.01.09

542 Santos JM, Vrandečić K, Ćosić T, Duvnjak T, Phillips AJL. 2011. Resolving the Diaporthe 543 species occurring on soybean in Croatia. Persoonia 27:9-19. 
544 Santos JM, Correia VG, Phillips A JL. 2010. Primers for mating-type diagnosis in Diaporthe and 545 Phomopsis: their use in teleomorph induction in vitro and biological species definition. Fungal 546 Biology 114:255-270. DOI: 10.1016/j.funbio.2010.01.007

547 Santos, J. and Phillips, A.J.L. 2009. Resolving the complex of Diaporthe (Phomopsis) species 548 occurring on Foeniculum vulgare in Portugal. Fungal Diversity, 34:111-125.

549 Savitha J, Bhargavi SD, Praveen VK. 2016. Complete Genome Sequence of the Endophytic 550 Fungus Diaporthe (Phomopsis) ampelina. Genome Announcements 4 (3): e0477-16.

551 Schilder AMC, Erincik O, Castlebury L, Rossman A, Ellis MA. 2005. Characterization of 552 Phomopsis spp. Infecting Grapevines in the Great Lakes Region of North America. Plant 553 Disease 89(7):755-762. DOI: 10.1094/PD-89-0755.

554 Schoch CL, Seifert KA, Huhndorf S, Robert V, Spouge JL, Levesque CA and Chen W. 2012. 555 Nuclear ribosomal internal transcribed spacer (ITS) region as a universal DNA barcode marker 556 for fungi. Proceedings of the National Academy of Sciences of the United States of America 557 109(16):6241-6246. DOI: 10.1073/pnas.1117018109.

558 Shenoy BD, Jeewon R, Hyde KD. 2007. Impact of DNA sequence-data on the taxonomy of 559 anamorphic fungi. Fungal Diversity 26:1-54.

560 Shishido M, Yoshida N, Usami T, Shinozaki T, Kobayashi M, Takeuchi T. 2006. Black root rot 561 of cucurbits caused by Phomopsis sclerotioides in Japan and phylogenetic grouping of the 562 pathogen. Journal of General Plant Pathology 72:220-227. DOI: 10.1007/s10327-006-0273-0.

563 Sun S, Van K, Kim MY, Min KH, Lee Y, Lee S. 2012. Diaporthe phaseolorum var. caulivora, a 564 Causal Agent for Both Stem Canker and Seed Decay on Soybean. The Plant Pathology Journal 565 28(1):55-59. DOI:10.5423/PPJ.NT.10.2011.0194.

566 Sun S, Kim MY, Chaisan T, Lee Y, Van K, Lee S. 2013. Phomopsis (Diaporthe) Species as the 567 Cause of Soybean Seed Decay in Korea. Journal of Phytopathology 161:131-134. 568 DOI:10.1111/jph.12034.

569 Sutton DA, Timm WD, Morgan-Jones G, Rinaldi MG. 1999. Human phaeohyphomycotic 570 osteomyelitis caused by the coelomycete Phomopsis saccardo 1905: criteria for identification, 571 case history, and therapy. Journal of Clinical Microbiology 37(3):807-811.

572 Tan YP, Edwards J, Grice KRE, Shivas RG. 2013. Molecular phylogenetic analysis reveals six 573 new species of Diaporthe from Australia. Fungal Diversity 61:251-260. DOI:10.1007/s13225574 013-0242-9.

575 Tamura K. 1992 Estimation of the number of nucleotide substitutions when there are strong 576 transition-transversion and G + C-content biases. Molecular Biology and Evolution 9:678-687. 
577 Tamura K, Nei M. 1993. Estimation of the number of nucleotide substitutions in the control 578 region of mitochondrial DNA in humans and chimpanzees. Molecular Biology and Evolution $579 \quad 10: 512-526$.

580 Tamura K, Stecher G, Peterson D, Filipski A, Kumar S. 2013. MEGA6: Molecular Evolutionary 581 Genetics Analysis version 6.0. Molecular Biology and Evolution. DOI: 10.1093/molbev/mst197

582 Thangaduras D, Sangeetha J. 2013. Bioinformatics Tools for the Multilocus Phylogenetic 583 Analysis of Fungi. In: Gupta VK, Tuohy MG, Ayyachamy M, Turner KM, O’Donovan A, eds. 584 Laboratory Protocols in Fungal Biology. New York: Springer New York, 579-592. 585 DOI:10.1007/978-1-4614-2356-0

586 Thompson SM, Tan YP, Young AJ, Neate SM, Aitken EAB, Shivas RG. 2011. Stem cankers on 587 sunflower (Helianthus annuus) in Australia reveal a complex of pathogenic Diaporthe 588 (Phomopsis) species. Persoonia 27:80-89.

589 Udayanga D, Castlebury LA, Rossman LA, Chukeatirote E, Hyde KD. 2014a. Insights into the 590 genus Diaporthe: phylogenetic species delimitation in the D. eres species complex. Fungal 591 Diversity 64:203-229. DOI: 10.1007/s13225-014-0297-2.

592 Udayanga D, Castlebury LA, Rossman AY, Hyde KD. 2014b. Species limits in Diaporthe: 593 molecular re-assessment of D. citri, D. cytosporella, D. foeniculina and D. rudis. Persoonia 594 32:83-101.

595 Udayanga D, Liu X, Crous PW, McKenzie EHC, Chukeatirote E, Hyde KD. 2012. A multi-locus 596 phylogenetic evaluation of Diaporthe (Phomopsis). Fungal Diversity 56:157-171. DOI: 597 10.1007/s13225-012-0190-9.

598 Udayanga D, Liu X, McKenzie EHC, Chukeatirote E, Bahkali AHA, Hyde KD. 2011. The genus 599 Phomopsis: biology, applications, species concepts and names of common phytopathogens. 600 Fungal Diversity 50:189-225. DOI: 10.1007/s13225-011-0126-9.

601 Van Niekerk JM, Groenewald JZ, Farr DF, Fourie PH, Halleen F, Crous PW. 2005. 602 Reassessment of Phomopsis species on grapevines. Australasian Plant Pathology 34:27-39.

603 Van Rensburg JCJ, Lamprecht SC, Groenewald JZ, Castlebury LA, Crous PW. 2006. 604 Characterisation of Phomopsis spp. associated with die-back of rooibos (Aspalathus linearis) in 605 South Africa. Studies in Mycology 55:65-74.

606 Van Warmelo KT, Marasas WFO. 1972. Phomopsis leptostromiformis: the causal fungus of 607 lupinosis, a mycotoxicosis, in sheep. Mycologia 64:316-324. 
608 Vidić M, Petrović K, Đorđević V, Riccioni L. 2013. Occurrence of Phomopsis longicolla $\beta$ 609 Conidia in Naturally Infected Soybean. Journal of Phytopathology 161:470-477. DOI: 610 10.1111/jph.12092

611 Walker DM, Castlebury LA, Rossman AY, White Jr. JF. 2012. New molecular markers for 612 fungal phylogenetics: Two genes for species-level systematics in the Sordariomycetes 613 (Ascomycota). Molecular Phylogenetics and Evolution 64:500-512.

614 Wang J, Xu X, Mao L, Lao J, Lin F, Yuan Z, Zhang C. 2014. Endophytic Diaporthe from 615 Southeast China are genetically diverse based on multi-locus phylogeny analyses. World Journal 616 of Microbiology \& Biotechnology 30:237-243. DOI: 10.1007/s11274-013-1446-6.

617 Webber JG, Gibbs JN. 1984. Colonization of elm bark by Phomopsis oblonga. Transactions of 618 the British Mycological Society 82:348-352.

619 Woese CR, Fox GE. 1977. Phylogenetic structure of the prokaryotic domain: the primary 620 kingdoms. Proceedings of the National Academy of Sciencies of the United States of America 621 74(11):5088-5090. 
Figure 1

Figure 1 - MP condensed tree with a $90 \%$ cut-off, build using the five loci TEF1-TUB-CAL-HIS-ITS for the 96 Diaporthe species.

Ex-type or ex-epitype or isotype isolates are represented in bold. 


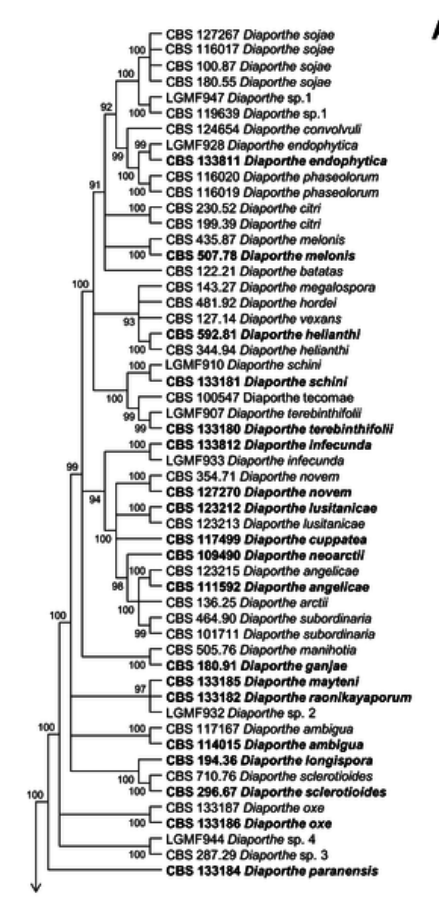

A
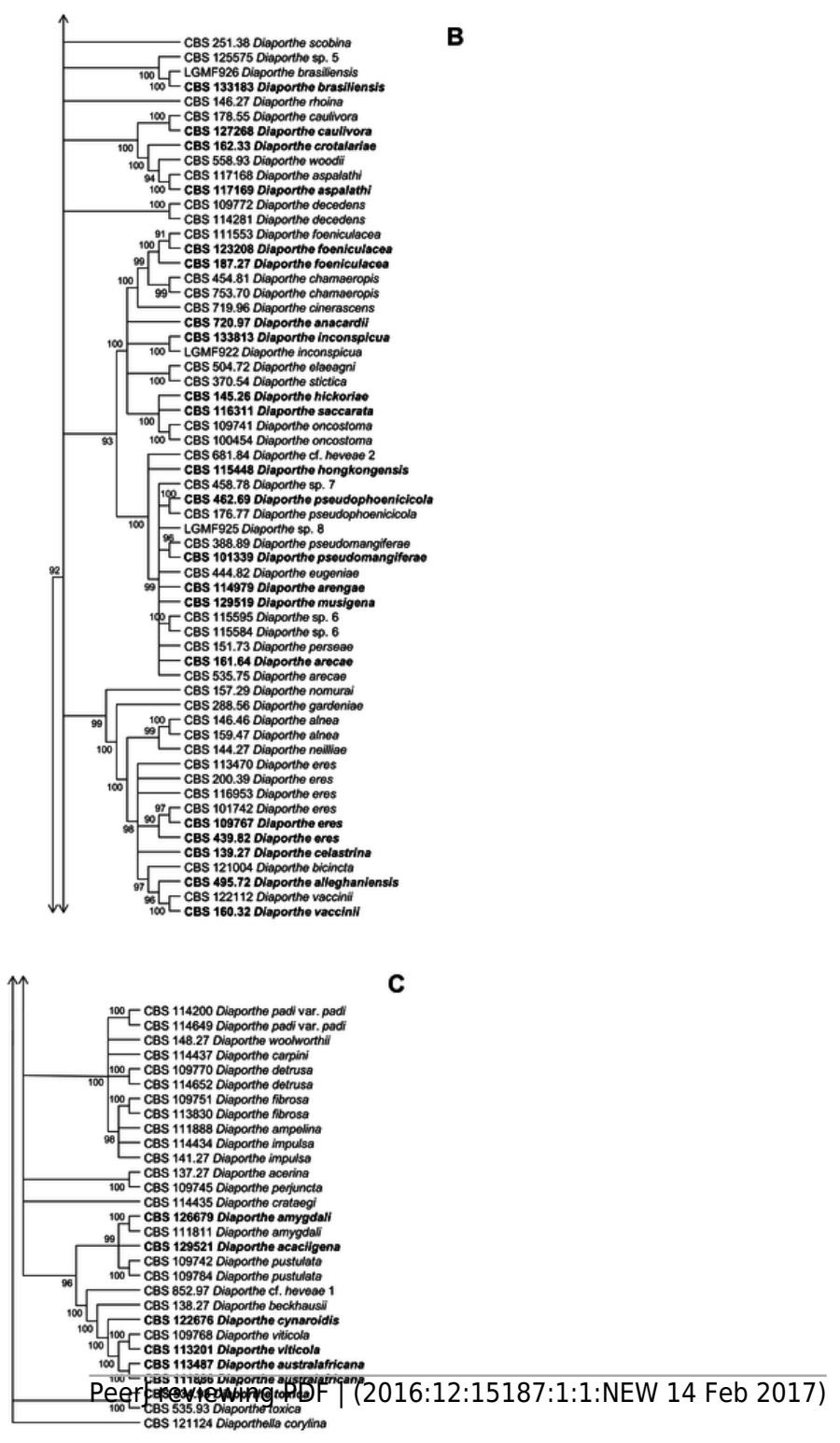
Figure 2

Figure 2 - ML condensed tree with a $90 \%$ cut-off, build using the five loci TEF1-TUB-CAL-HIS-ITS for the 96 Diaporthe species.

The percentage of trees in which the associated taxa clustered together is shown next to the branches. Ex-type, ex-epitype, or isotype isolates are represented in bold. 

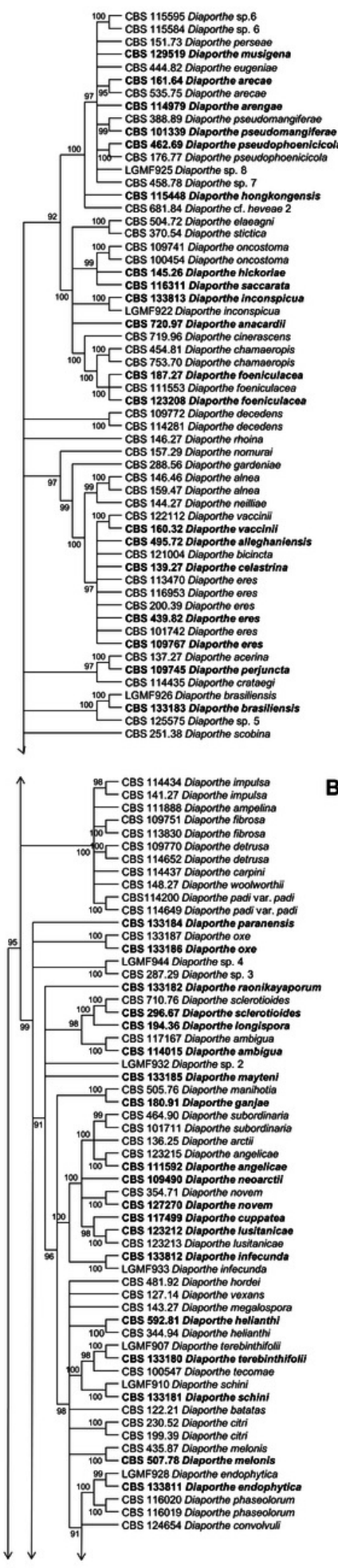

B

A 


\section{Figure 3}

Figure 3 - MP condensed tree with a 90\% cut-off build using the TEF1 locus for the 96 Diaporthe species.

This locus generates the best single locus trees for the MP method. Ex-type, ex-epitype, or isotype isolates are represented in bold 

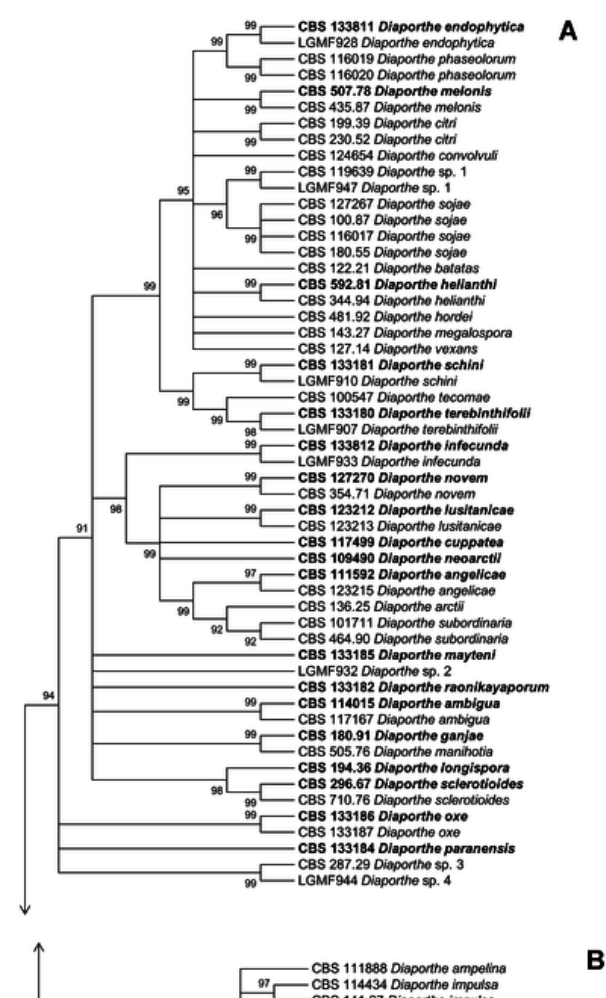

B
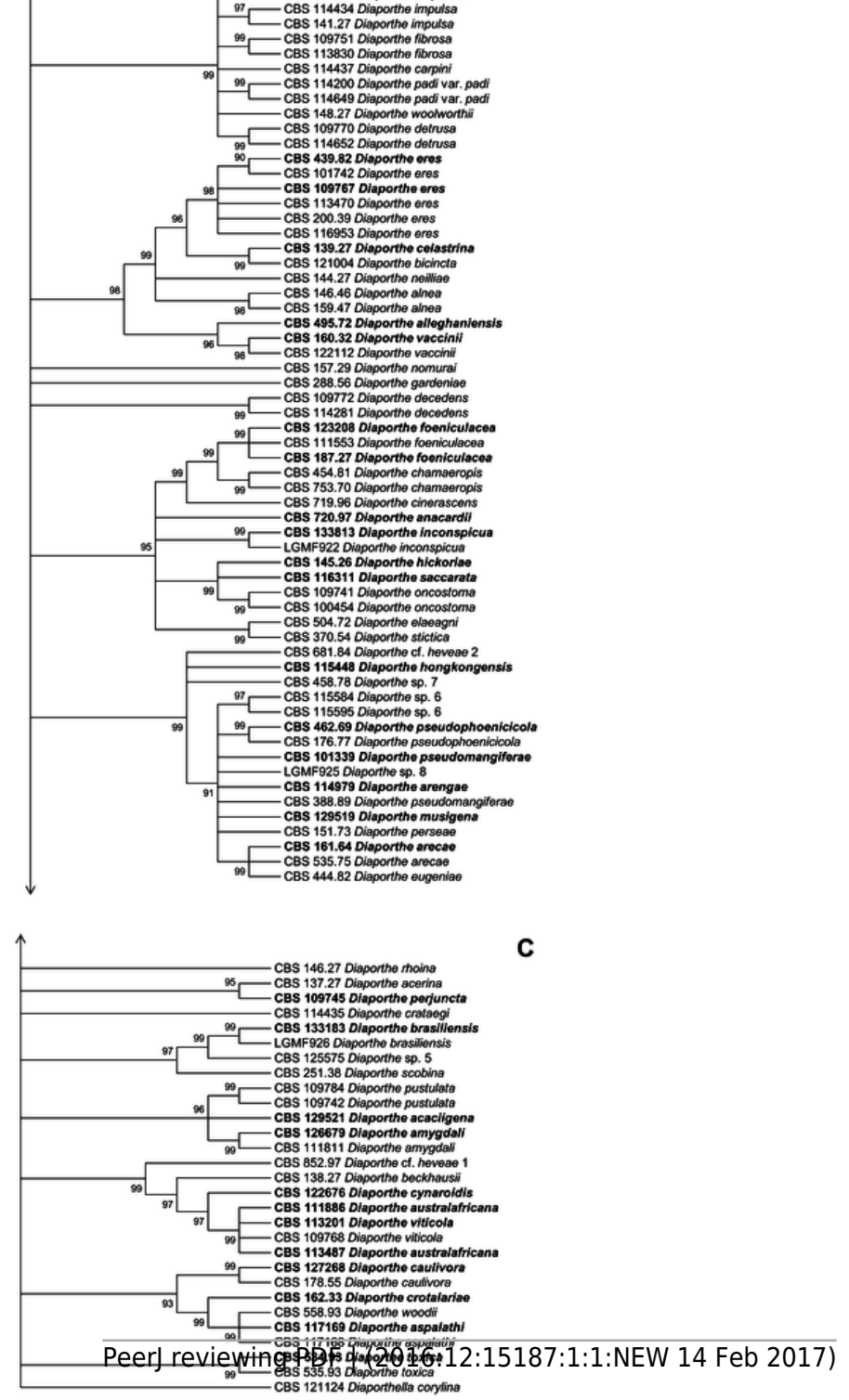


\section{Figure 4}

Figure 4 - ML condensed tree with a 90\% cut-off, build using the TEF1 locus for the 96 Diaporthe species.

This locus generates the best single locus trees for the ML method. The percentage of trees in which the associated taxa clustered together is shown next to the branches. Ex-type, exepitype, or isotype isolates are represented in bold. 

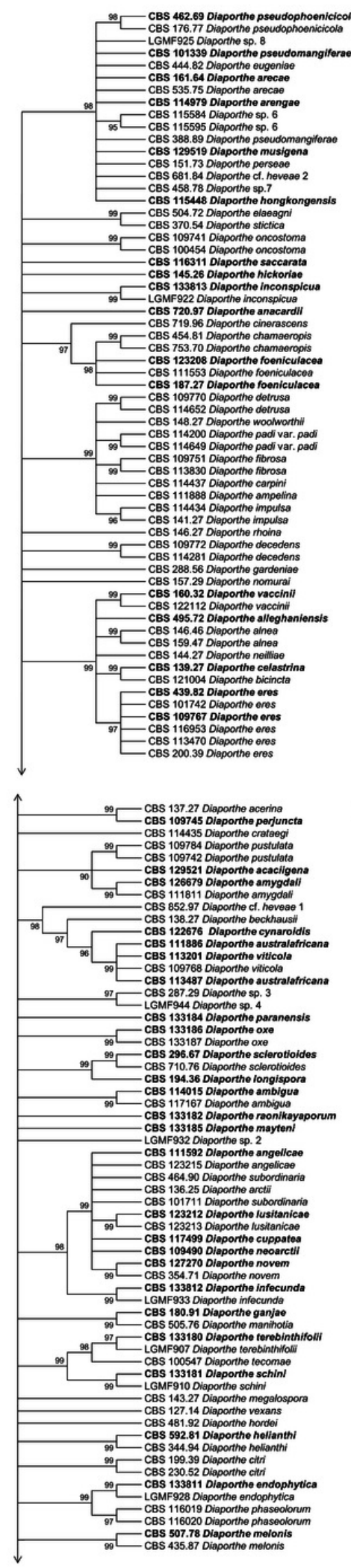

\section{A}

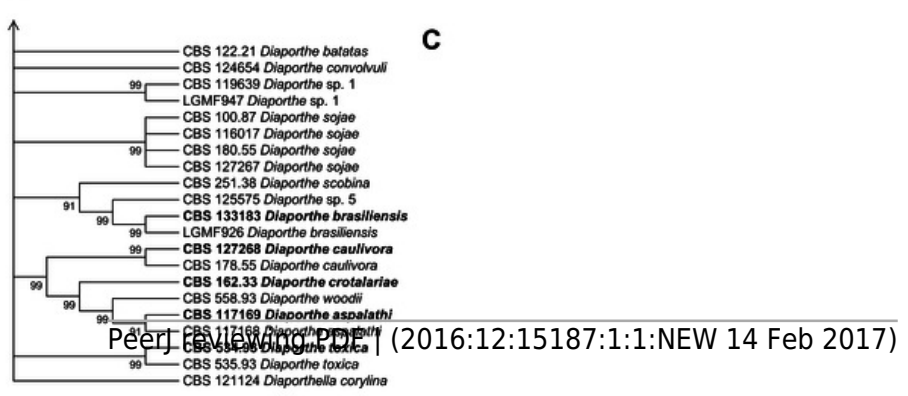




\section{Figure 5}

Figure 5 - Profiles of phylogenetic informativeness for the 96 Diaporthe species and 5 loci.
A) Net Phylogenetic informativeness. B) Phylogenetic informativeness per site. 

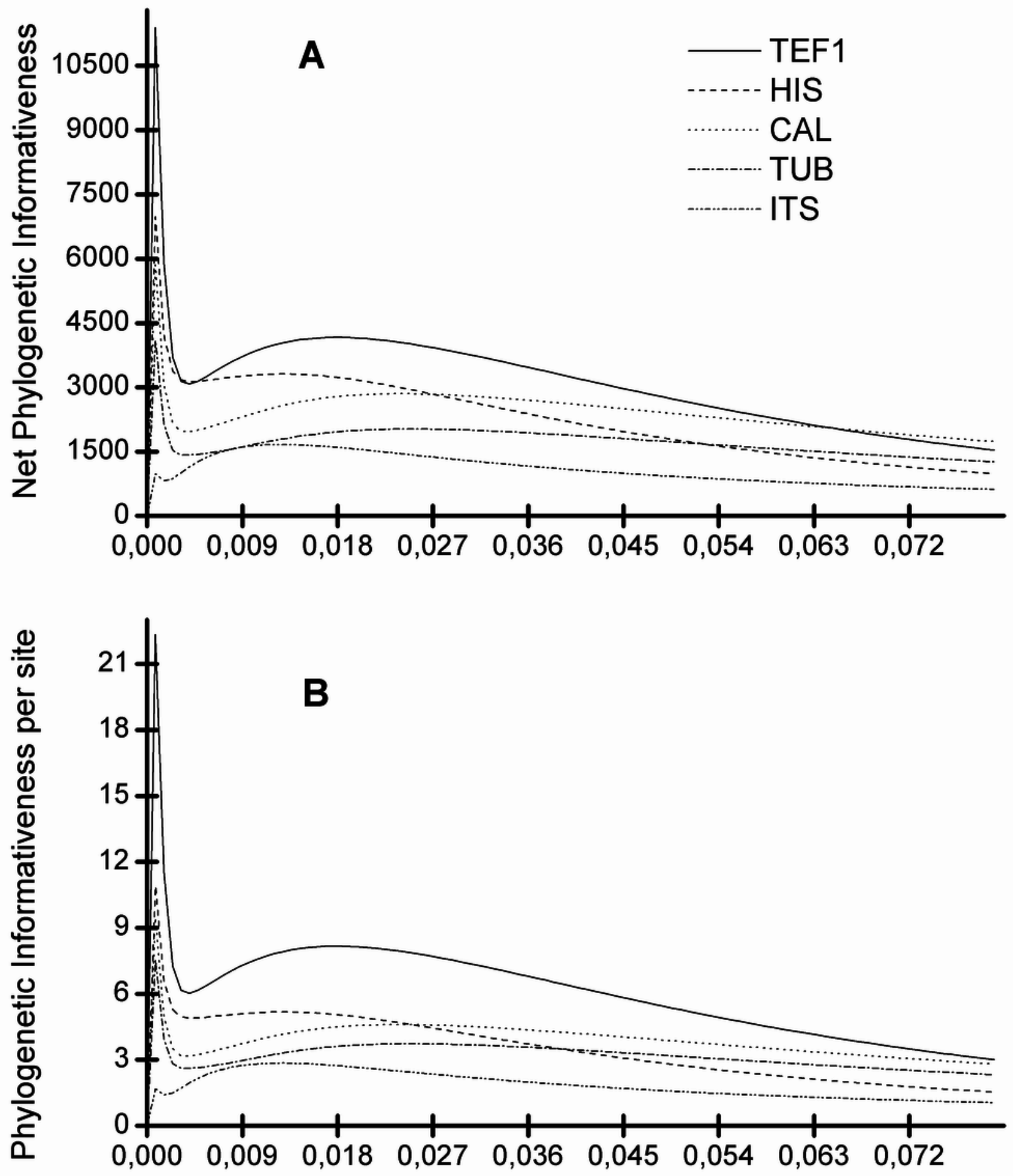


\section{Table $\mathbf{1}$ (on next page)}

Models used to construct the ML trees. 
Tree

\begin{tabular}{|c|c|c|}
\hline & & \\
\hline ITS & Tamura-Nei & Tamura \& Nei, 1993 \\
\hline TEF1 & Hasegawa-Kishino-Yano & Hasegawa, Kishino \& Yano, 1985 \\
\hline TUB & Hasegawa-Kishino-Yano & Hasegawa, Kishino \& Yano, 1985 \\
\hline HIS & General Time Reversible & Nei \& Kumar, 2000 \\
\hline $\mathrm{CAL}$ & Tamura 3-parameter & Tamura, 1992 \\
\hline ITS - TEF1 & Tamura-Nei & Tamura \& Nei, 1993 \\
\hline ITS - TUB & Tamura-Nei & Tamura \& Nei, 1993 \\
\hline ITS - HIS & Tamura-Nei & Tamura \& Nei, 1993 \\
\hline ITS - CAL & Tamura-Nei & Tamura \& Nei, 1993 \\
\hline TEF1 - TUB & Hasegawa-Kishino-Yano & Hasegawa, Kishino \& Yano, 1985 \\
\hline TEF1 - HIS & Tamura-Nei & Tamura \& Nei, 1993 \\
\hline TEF1 - CAL & Hasegawa-Kishino-Yano & Hasegawa, Kishino \& Yano, 1985 \\
\hline TUB - HIS & General Time Reversible & Nei \& Kumar, 2000 \\
\hline TUB - CAL & Hasegawa-Kishino-Yano & Hasegawa, Kishino \& Yano, 1985 \\
\hline HIS - CAL & Hasegawa-Kishino-Yano & Hasegawa, Kishino \& Yano, 1985 \\
\hline ITS - TEF1 - TUB & Tamura-Nei & Tamura \& Nei, 1993 \\
\hline ITS - TEF1 - HIS & General Time Reversible & Nei \& Kumar, 2000 \\
\hline ITS - TEF1 - CAL & Tamura-Nei & Tamura \& Nei, 1993 \\
\hline ITS - TUB -HIS & General Time Reversible & Nei \& Kumar, 2000 \\
\hline ITS - TUB - CAL & Tamura-Nei & Tamura \& Nei, 1993 \\
\hline ITS - HIS - CAL & Tamura-Nei & Tamura \& Nei, 1993 \\
\hline TEF1 - TUB - HIS & General Time Reversible & Nei \& Kumar, 2000 \\
\hline TEF1 - TUB - CAL & Hasegawa-Kishino-Yano & Hasegawa, Kishino \& Yano, 1985 \\
\hline TEF1 - HIS - CAL & Tamura-Nei & Tamura \& Nei, 1993 \\
\hline TUB - HIS - CAL & Hasegawa-Kishino-Yano & Hasegawa, Kishino \& Yano, 1985 \\
\hline ITS - TEF1 - TUB - HIS & General Time Reversible & Nei \& Kumar, 2000 \\
\hline ITS - TEF1 - TUB - CAL & Tamura-Nei & Tamura \& Nei, 1993 \\
\hline ITS - TEF1 - HIS - CAL & Tamura-Nei & Tamura \& Nei, 1993 \\
\hline ITS - TUB - HIS - CAL & Tamura-Nei & Tamura \& Nei, 1993 \\
\hline TEF1 - TUB - HIS - CAL & Hasegawa-Kishino-Yano & Hasegawa, Kishino \& Yano, 1985 \\
\hline ITS - TEF1 - TUB - HIS - CAL & General Time Reversible & Nei \& Kumar, 2000 \\
\hline
\end{tabular}

1

2

3

4

5

6

7

8

9 
Table 2 (on next page)

MP trees scores. 


\begin{tabular}{|c|c|c|c|c|c|c|c|}
\hline Tree & $\begin{array}{l}\text { No. } \\
\text { trees }\end{array}$ & Length & $\begin{array}{c}\text { Normalized } \\
\text { length }\end{array}$ & $\begin{array}{c}\text { Consistency } \\
\text { index }\end{array}$ & $\begin{array}{c}\text { Retention } \\
\text { index }\end{array}$ & $\begin{array}{c}\text { Composite } \\
\text { index }\end{array}$ & $\begin{array}{c}\text { Parsimony-informative } \\
\text { sites }\end{array}$ \\
\hline \multicolumn{8}{|l|}{ lgene } \\
\hline ITS & 1 & 1200 & 1.970 & 0.278906 & 0.765634 & 0.244365 & 0.213540 \\
\hline TEF1 & 1 & 2830 & 4.647 & 0.280810 & 0.773915 & 0.229713 & 0.217323 \\
\hline TUB & 1 & 1628 & 2.673 & 0.349176 & 0.785012 & 0.289798 & 0.274107 \\
\hline HIS & 1 & 1880 & 3.087 & 0.285557 & 0.729297 & 0.224608 & 0.208256 \\
\hline CAL & 1 & 2234 & 3.668 & 0.355136 & 0.816321 & 0.304750 & 0.289905 \\
\hline \multicolumn{8}{|l|}{2 genes } \\
\hline ITS-TEF1 & 1 & 4218 & 6.926 & 0.267368 & 0.756266 & 0.219278 & 0.202201 \\
\hline ITS-TUB & 1 & 2977 & 4.888 & 0.303147 & 0.758804 & 0.250811 & 0.230029 \\
\hline ITS-HIS & 1 & 3268 & 5.366 & 0.266073 & 0.721901 & 0.212506 & 0.192078 \\
\hline ITS-CAL & 1 & 3657 & 6.005 & 0.308194 & 0.780338 & 0.259686 & 0.240496 \\
\hline TEF1-TUB & 2 & 4535 & 7.447 & 0.300317 & 0.772148 & 0.245351 & 0.231889 \\
\hline TEF1-HIS & 1 & 4828 & 7.928 & 0.275606 & 0.749486 & 0.220282 & 0.206562 \\
\hline TEF1-CAL & 1 & 5206 & 8.548 & 0.304724 & 0.784949 & 0.252402 & 0.239193 \\
\hline TUB-HIS & 1 & 3606 & 5.921 & 0.306263 & 0.746843 & 0.244391 & 0.228730 \\
\hline TUB-CAL & 1 & 3975 & 6.527 & 0.342310 & 0.795145 & 0.287052 & 0.272186 \\
\hline HIS-CAL & 1 & 4267 & 7.007 & 0.311460 & 0.770357 & 0.255101 & 0.239935 \\
\hline \multicolumn{8}{|l|}{3 genes } \\
\hline ITS-TEF1-TUB & 1 & 5942 & 9.757 & 0.285318 & 0.758687 & 0.232892 & 0.216467 \\
\hline ITS-TEF1-HIS & 3 & 6233 & 10.235 & 0.266876 & 0.740786 & 0.214166 & 0.197698 \\
\hline ITS-TEF1-CAL & 1 & 6609 & 10.852 & 0.290524 & 0.771371 & 0.240083 & 0.224102 \\
\hline ITS-TUB-HIS & 1 & 4989 & 8.192 & 0.288178 & 0.737853 & 0.231161 & 0.212633 \\
\hline ITS-TUB-CAL & 1 & 5378 & 8.831 & 0.315121 & 0.775889 & 0.262285 & 0.244499 \\
\hline ITS-HIS-CAL & 2 & 5661 & 9.296 & 0.293677 & 0.757132 & 0.240207 & 0.222352 \\
\hline TEF1-TUB-CAL & 1 & 6910 & 11.346 & 0.311702 & 0.781378 & 0.257255 & 0.243557 \\
\hline TEF1-TUB-HIS & 1 & 6537 & 10.734 & 0.290338 & 0.754311 & 0.233090 & 0.219005 \\
\hline TEF1-HIS-CAL & 1 & 7209 & 11.837 & 0.294419 & 0.766557 & 0.239569 & 0.225689 \\
\hline TUB-HIS-CAL & 1 & 5962 & 9.790 & 0.318135 & 0.770532 & 0.260290 & 0.245133 \\
\hline \multicolumn{8}{|l|}{4 genes } \\
\hline ITS-TEF1-TUB-HIS & 1 & 7934 & 13.028 & 0.281222 & 0.747108 & 0.226279 & 0.210103 \\
\hline ITS-TEF1-TUB-CAL & 1 & 8326 & 13.672 & 0.298775 & 0.770405 & 0.245945 & 0.230178 \\
\hline ITS-TEF1-HIS-CAL & 1 & 8622 & 14.158 & 0.284827 & 0.757809 & 0.231684 & 0.215844 \\
\hline ITS-TUB-HIS-CAL & 1 & 7364 & 12.092 & 0.302877 & 0.759944 & 0.247364 & 0.230170 \\
\hline TEF1-TUB-HIS-CAL & 2 & 8911 & 14.632 & 0.301867 & 0.767101 & 0.245686 & 0.231563 \\
\hline \multicolumn{8}{|l|}{5 genes } \\
\hline $\begin{array}{l}\text { ITS-TEF1-TUB-HIS-CAL } \\
\quad 1\end{array}$ & 1 & 10327 & 16.957 & 0.292768 & 0.759604 & 0.238098 & 0.222388 \\
\hline \multicolumn{8}{|l|}{2} \\
\hline \multicolumn{8}{|l|}{3} \\
\hline \multicolumn{8}{|l|}{4} \\
\hline \multicolumn{8}{|l|}{5} \\
\hline \multicolumn{8}{|l|}{6} \\
\hline 7 & & & & & & & \\
\hline
\end{tabular}




\section{Table 3 (on next page)}

Data from the likelihood values using ML trees. 


\begin{tabular}{lrc}
\hline \multicolumn{1}{c}{ Tree } & $-\log$ Likelihood & $\begin{array}{c}\text { Normalizad } \\
\text { - log Likelihood }\end{array}$ \\
\hline 1 gene & & \\
ITS & -6778.9324 & -11.1313 \\
TEF1 & -12771.9747 & -20.9720 \\
TUB & -8921.3230 & -14.6491 \\
HIS & -9330.7481 & -15.3214 \\
CAL & -11.756 .6407 & -19.3048 \\
2 genes & & \\
ITS-TEF1 & -20494.0008 & -33.6519 \\
ITS-TUB & -16381.1047 & -26.8984 \\
ITS-HIS & -16835.4062 & -27.6443 \\
ITS-CAL & -19449.5000 & -31.9368 \\
TEF1-TUB & -22209.9657 & -36.4696 \\
TEF1-HIS & -22707.1478 & -37.2860 \\
TEF1-CAL & -25263.7157 & -41.4839 \\
TUB-HIS & -18720.0479 & -30.7390 \\
TUB-CAL & -21286.5020 & -34.9532 \\
HIS-CAL & -21896.7086 & -35.9552 \\
3 genes & & \\
ITS-TEF1-TUB & -29959.8491 & -49.1952 \\
ITS-TEF1-HIS & -30409.1656 & -49.9329 \\
ITS-TEF1-CAL & -33105.3032 & -54.3601 \\
ITS-TUB-HIS & -26256.8160 & -43.1146 \\
ITS-TUB-CAL & -29008.0228 & -47.6322 \\
ITS-HIS-CAL & -29425.9498 & -48.3185 \\
TEF1-TUB-CAL & -34699.3754 & -56.9776 \\
TEF1-TUB-HIS & -32201.5900 & -52.8762 \\
TEF1-HIS-CAL & -35160.1260 & -57.7342 \\
TUB-HIS-CAL & -31194.9713 & -51.2233 \\
4 genes & & -65.5999 \\
ITS-TEF1-TUB-HIS & -39950.3574 & -69.9092 \\
ITS-TEF1-TUB-CAL & -42574.6960 & -63.8144 \\
ITS-TEF1-HIS-CAL & -42940.9069 & -73.2480 \\
ITS-TUB-HIS-CAL & -38862.9726 & \\
TEF1-TUB-HIS-CAL & -44608.0234 & \\
5 genes & & \\
ITS-TEF1-TUB-HIS-CAL & -52626.8115 & \\
& & \\
\hline
\end{tabular}

1

2 


\section{Table 4(on next page)}

Alignments characteristics. 


\begin{tabular}{|c|c|c|c|c|}
\hline Locus & $\begin{array}{c}\text { No. } \\
\text { Characters }\end{array}$ & $\begin{array}{l}\text { No. Conserved } \\
\text { sites (in \%) }\end{array}$ & $\begin{array}{l}\text { No. variable } \\
\text { sites (in \%) }\end{array}$ & $\begin{array}{l}\text { No. Parsim-info } \\
\text { sites (in \%) }\end{array}$ \\
\hline \multicolumn{5}{|l|}{1 gene } \\
\hline ITS & 609 & $350(57)$ & 235 (39) & $177(29)$ \\
\hline TEF1 & 535 & $128(24)$ & $382(71)$ & $328(61)$ \\
\hline TUB & 603 & $220(36)$ & $323(54)$ & $279(46)$ \\
\hline HIS & 688 & $329(48)$ & $311(45)$ & $259(38)$ \\
\hline CAL & 667 & $194(29)$ & $425(64)$ & $370(55)$ \\
\hline \multicolumn{5}{|l|}{2 genes } \\
\hline ITS-TEF1 & 1149 & $478(42)$ & $617(54)$ & $505(44)$ \\
\hline ITS-TUB & 1217 & $570(47)$ & $558(46)$ & $456(37)$ \\
\hline ITS-HIS & 1302 & $679(52)$ & $546(42)$ & $436(33)$ \\
\hline ITS-CAL & 1281 & $544(42)$ & $660(52)$ & $547(43)$ \\
\hline TEF1-TUB & 1143 & $348(30)$ & $705(62)$ & $607(53)$ \\
\hline TEF1-HIS & 1228 & 457 (37) & $693(56)$ & $587(48)$ \\
\hline TEF1-CAL & 1207 & $322(27)$ & 807 (67) & $698(58)$ \\
\hline TUB-HIS & 1296 & $549(42)$ & 634 (49) & $538(42)$ \\
\hline TUB-CAL & 1275 & $414(32)$ & 748 (59) & $649(51)$ \\
\hline HIS-CAL & 1360 & $523(38)$ & $736(54)$ & $629(46)$ \\
\hline \multicolumn{5}{|l|}{3 genes } \\
\hline ITS-TEF1-TUB & 1757 & $698(40)$ & $940(54)$ & $784(45)$ \\
\hline ITS-TEF1-HIS & 1842 & 807 (44) & $928(50)$ & $764(41)$ \\
\hline ITS-TEF1-CAL & 1821 & $672(37)$ & $1042(57)$ & $875(48)$ \\
\hline ITS-TUB-HIS & 1910 & 899 (47) & $869(45)$ & $715(37)$ \\
\hline ITS-TUB-CAL & 1889 & $764(40)$ & $983(52)$ & $826(44)$ \\
\hline ITS-HIS-CAL & 1974 & $873(44)$ & $971(49)$ & $806(41)$ \\
\hline TEF1-TUB-CAL & 1815 & $542(30)$ & $1130(62)$ & $977(54)$ \\
\hline TEF1-TUB-HIS & 1836 & 677 (379) & $1016(55)$ & $866(47)$ \\
\hline TEF1-HIS-CAL & 1900 & $651(34)$ & $1118(59)$ & $957(50)$ \\
\hline TUB-HIS-CAL & 1968 & $743(38)$ & $1059(54)$ & $908(46)$ \\
\hline \multicolumn{5}{|l|}{4 genes } \\
\hline ITS-TEF1-TUB-HIS & 2450 & $1027(42)$ & $1251(51)$ & $1043(43)$ \\
\hline ITS-TEF1-TUB-CAL & 2429 & $892(37)$ & $1365(56)$ & $1154(48)$ \\
\hline ITS-TEF1-HIS-CAL & 2514 & $1001(40)$ & $1353(54)$ & $1134(45)$ \\
\hline ITS-TUB-HIS-CAL & 2582 & $1093(42)$ & $1294(50)$ & $1085(42)$ \\
\hline TEF1-TUB-HIS-CAL & 2508 & $871(35)$ & $1441(57)$ & $1236(49)$ \\
\hline \multicolumn{5}{|l|}{5 genes } \\
\hline ITS-TEF1-TUB-HIS-CAL & 3102 & $1221(39)$ & $1676(54)$ & $1413(46)$ \\
\hline
\end{tabular}




\section{Table 5 (on next page)}

Average changes in tree resolution when a locus is added or removed.

Each row indicates the locus that is added to the trees. Each column indicates the difference between trees build using $n$ or $n-1$ loci. For example, row ITS, columns $4 \rightarrow 3$, indicate the average differences between every pair of 3 and 4 loci trees that include the ITS locus, using either a MP or a ML approach. The higher the number, the more different the two trees in the pair are, on average. "Average" columns indicate the average changes for all columns when a specific locus is considered. Darker cells indicate smaller average changes (and thus smaller information losses) when a locus is added from phylogenetic trees 


\begin{tabular}{|c|c|c|c|c|c|c|c|c|c|c|c|}
\hline \multicolumn{6}{|c|}{ MP } & \multicolumn{6}{|c|}{ ML } \\
\hline & $5 \rightarrow 4$ & $4 \rightarrow 3$ & $3 \rightarrow 2$ & $2 \rightarrow 1$ & Overall & & $5 \rightarrow 4$ & $4 \rightarrow 3$ & $3 \rightarrow 2$ & $2 \rightarrow 1$ & Overall \\
\hline ITS & 1.416 & 1.407 & 31.9 & 36.875 & 17.8995 & ITS & 12 & 23.75 & 24.38888889 & 31.75 & 22.9722222 \\
\hline TEF1 & 2.963 & 2.95075 & 44.7333333 & 44.375 & 23.7555208 & TEF1 & 22 & 25.25 & 30.6111111 & 42.25 & 30.0277778 \\
\hline TUB & 1.705 & 1.70575 & 41.4 & 43.75 & 22.1401875 & TUB & 16 & 24.375 & 28.66666667 & 41.375 & 27.6041667 \\
\hline HIS & 2.001 & 1.998 & 41.2 & 40.5 & 21.42475 & HIS & 12 & 19 & 24.8888889 & 37 & 23.2222222 \\
\hline CAL & 2.393 & 29 & 42.6 & 42.125 & 29.0295 & CAL & 10 & 24.5 & 25.3333333 & 39.125 & 24.7395833 \\
\hline
\end{tabular}

